\section{(6) OPEN ACCESS}

\title{
Prospective evaluation of respiratory exacerbations in children with cystic fibrosis from newborn screening to 5 years of age
}

\author{
Catherine Ann Byrnes, ${ }^{1,2}$ Suzanna Vidmar, ${ }^{3,4}$ Joyce L Cheney, ${ }^{5,6}$ John B Carlin, ${ }^{3,4}$ \\ David S Armstrong, ${ }^{7}$ Peter J Cooper, ${ }^{8}$ Keith Grimwood, ${ }^{5,9}$ Marj Moodie, ${ }^{10}$ \\ Colin F Robertson, ${ }^{11}$ Margaret Rosenfeld, ${ }^{12,13}$ Harm A Tiddens, ${ }^{14}$ \\ Claire E Wainwright, ${ }^{5,6}$ for the ACFBAL Study Investigators
}

For numbered affiliations see end of article.

\section{Correspondence to} Dr Catherine Ann Byrnes, Department of Paediatrics, Faculty of Medical and Health Sciences, University of Auckland, PO Box 92019, Auckland 1301, New Zealand; c.byrnes@auckland.ac.nz

Received 26 June 2012 Revised 16 December 2012 Accepted 18 December 2012 Published Online First 23 January 2013

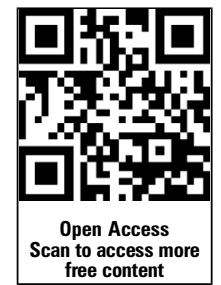

\section{SLinked}

- http://dx.doi.org/10.1136/ thoraxjnl-2013-203262

To cite: Byrnes CA, Vidmar $S$, Cheney JL, et al. Thorax 2013;68:643-651.

\section{ABSTRACT}

Background Newborn screening allows novel treatments for cystic fibrosis (CF) to be trialled in early childhood before irreversible lung injury occurs. As respiratory exacerbations are a potential trial outcome variable, we determined their rate, duration and clinical features in preschool children with CF; and whether they were associated with growth, lung structure and function at age 5 years.

Methods Respiratory exacerbations were recorded prospectively in Australasian CF Bronchoalveolar Lavage trial subjects from enrolment after newborn screening to age 5 years, when all participants underwent clinical assessment, chest $\mathrm{CT}$ scans and spirometry.

Results 168 children (88 boys) experienced 2080 exacerbations, at an average rate of 3.66 exacerbations per person-year; $80.1 \%$ were community managed and $19.9 \%$ required hospital admission. There was an average increase in exacerbation rate of $9 \%(95 \% \mathrm{Cl}$ $4 \%$ to $14 \% ; p<0.001)$ per year of age. Exacerbation rate differed by site $(p<0.001)$ and was $26 \%$ lower $(95 \% \mathrm{Cl} 12 \%$ to $38 \%)$ in children receiving 12 months of prophylactic antibiotics. The rate of exacerbations in the first 2 years was associated with reduced forced expiratory volume in $1 \mathrm{~s}$ z scores. Ever having a hospitalmanaged exacerbation was associated with bronchiectasis (OR 2.67, 95\% Cl 1.13 to 6.31 ) in chest CT scans, and lower weight z scores at 5 years of age (coefficient $-0.39,95 \% \mathrm{Cl}-0.74$ to -0.05 ).

Conclusions Respiratory exacerbations in young children are markers for progressive CF lung disease and are potential trial outcome measures for novel

treatments in this age group.

\section{INTRODUCTION}

The occurrence of respiratory exacerbations is being used increasingly as an outcome measure for intervention trials in cystic fibrosis (CF) lung disease, particularly in relatively healthy infants and young children with this disorder. ${ }^{1}$ While exacerbations in older patients are associated with an accelerated decline in lung function ${ }^{2}$ and reduced quality of life and survival, ${ }^{3}{ }^{4}$ the association between exacerbations in infants and preschool children and long-term outcomes remains unknown. Widespread adoption of newborn screening programmes will allow novel treatments

\section{Key messages}

What is the key question?

- What are the characteristics of respiratory exacerbations in preschool children with cystic fibrosis (CF) and are they associated with poorer lung structure and function by age 5 years?

\section{What is the bottom line?}

- Preschool children with CF had an average of three to four exacerbations per year, with frequency increasing with age and lower respiratory symptoms/signs reported more often in hospital-managed episodes. At age 5 years the exacerbation rate in the first 2 years of life was associated with lower forced expiratory volume in $1 \mathrm{~s}$ values and ever being admitted for a respiratory exacerbation was associated with an increased risk of bronchiectasis and lower weight-for-age z scores.

\section{Why read on?}

- Novel treatments to improve CF care are likely to be trialled increasingly in early childhood before irreversible lung injury occurs and respiratory exacerbations could become important outcome measures since they may act as markers for progressive lung disease.

to be introduced in early childhood before irreversible lung damage occurs. Despite being a familiar concept, a widely accepted standard definition of exacerbations in young children is lacking. The CF Foundation Clinical Practice Guidelines required changes in baseline for at least 3 of 11 parameters, but these were aimed at older patients. ${ }^{5}$ The Epidemiologic Study of CF, which includes one-third of patients with CF in Canada and the USA, reported that increased cough and new crackles were strong predictors of exacerbations in all age groups, with weight loss also a strong predictor in those younger than 6 years of age. ${ }^{6}$ For 'respiratory exacerbations' to be a useful and robust outcome measure in early childhood therapeutic 
Table 1 Respiratory exacerbations from enrolment to 5 years of age

\begin{tabular}{|c|c|c|c|c|c|}
\hline Parameters & Total number & Incidence per person-years & IRR & $95 \% \mathrm{Cl}$ & $p$ Value* \\
\hline \multicolumn{6}{|l|}{ Total respiratory exacerbations $(n=2080)$} \\
\hline \multicolumn{6}{|l|}{ Gender } \\
\hline Boys $(n=88)$ & 1123 & 3.83 & 1.10 & 0.93 to 1.30 & 0.261 \\
\hline Girls $(n=80)$ & 957 & 3.48 & & & \\
\hline \multicolumn{6}{|l|}{ Group } \\
\hline BAL $(n=84)$ & 1047 & 3.68 & 1.01 & 0.85 to 1.19 & 0.940 \\
\hline Std $(n=84)$ & 1033 & 3.65 & & & \\
\hline \multicolumn{6}{|c|}{ Anti-staphylococcal antibiotic prophylaxis for at least the first year of life } \\
\hline Yes $(n=54)$ & 516 & 2.94 & 0.74 & 0.62 to 0.88 & 0.001 \\
\hline No $(n=114)$ & 1564 & 3.99 & & & \\
\hline \multicolumn{6}{|l|}{ Pseudomonas aeruginosa } \\
\hline Ever $(n=101)$ & 1293 & 3.90 & 1.17 & 0.99 to 1.38 & 0.062 \\
\hline Never $(n=67)$ & 787 & 3.34 & & & \\
\hline \multicolumn{6}{|l|}{ Maternal smoking } \\
\hline Yes $(n=41)$ & 471 & 3.30 & 0.87 & 0.72 to 1.05 & 0.151 \\
\hline No $(n=127)$ & 1609 & 3.79 & & & \\
\hline \multicolumn{6}{|c|}{ Highest parental education level for both parents } \\
\hline Completed year $10(n=24)$ & 283 & 3.47 & 1.00 & & 0.766 \\
\hline Completed secondary education ( $n=39$ ) & 449 & 3.46 & 1.00 & 0.72 to 1.38 & \\
\hline Trade $(n=76)$ & 946 & 3.66 & 1.05 & 0.79 to 1.39 & \\
\hline Completed tertiary education $(n=17)$ & 236 & 3.98 & 1.14 & 0.83 to 1.58 & \\
\hline \multicolumn{6}{|l|}{ Age } \\
\hline $0-1$ year $(n=168)$ & 284 & 3.02 & 1.00 & & 0.007 \\
\hline$>1-2$ years $(n=165)$ & 411 & 3.36 & 1.11 & 0.94 to 1.31 & \\
\hline$>2-3$ years $(n=161)$ & 412 & 3.47 & 1.14 & 0.96 to 1.37 & \\
\hline$>3-4$ years $(n=159)$ & 468 & 4.10 & 1.36 & 1.12 to 1.64 & \\
\hline$>4-5+$ years $(n=158)$ & 505 & 4.20 & 1.39 & 1.15 to 1.68 & \\
\hline \multicolumn{6}{|l|}{ Total exacerbations ( $\mathrm{n=2080)}$} \\
\hline QLD (n=60) & 735 & 3.49 & & & $<0.001$ \\
\hline VIC ( $n=40)$ & 657 & 5.14 & & & \\
\hline NSW and SA $(n=42)$ & 385 & 2.85 & & & \\
\hline$N Z(n=26)$ & 303 & 3.22 & & & \\
\hline \multicolumn{6}{|c|}{ Exacerbations reported by clinic doctor $(n=1263)$} \\
\hline QLD (n=60) & 568 & 2.52 & & & $<0.001$ \\
\hline VIC $(n=40)$ & 202 & 1.21 & & & \\
\hline NSW and SA (n=42) & 290 & 2.03 & & & \\
\hline \multirow{2}{*}{$N Z(n=26)$} & 203 & 2.02 & & & \\
\hline & Total/number childrent & Incidence per person-years & IRR & $95 \% \mathrm{Cl}$ & $p$ Value* \\
\hline \multicolumn{6}{|c|}{ Respiratory exacerbations resulting in hospital admission ( $n=413)$} \\
\hline \multicolumn{6}{|l|}{ Parameters } \\
\hline Boys $(\mathrm{n}=88)$ & 225/64 & 0.62 & 1.11 & 0.81 to 1.52 & 0.507 \\
\hline Girls $(n=80)$ & $188 / 69$ & 0.55 & & & \\
\hline
\end{tabular}




\begin{tabular}{|c|c|c|c|c|c|}
\hline Parameters & Total number & Incidence per person-years & IRR & $95 \% \mathrm{Cl}$ & p Value* \\
\hline \multicolumn{6}{|l|}{ Group } \\
\hline BAL $(n=84)$ & $227 / 72$ & 0.64 & 1.22 & 0.87 to 1.72 & 0.240 \\
\hline Std $(n=84)$ & $186 / 61$ & 0.53 & & & \\
\hline \multicolumn{6}{|c|}{ Anti-staphylococcal antibiotic prophylaxis for at least the first year of life } \\
\hline Yes $(n=54)$ & $100 / 41$ & 0.47 & 0.74 & 0.54 to 1.02 & 0.066 \\
\hline No $(n=114)$ & $313 / 92$ & 0.63 & & & \\
\hline \multicolumn{6}{|l|}{ Pseudomonas aeruginosa } \\
\hline Ever $(n=101)$ & $315 / 92$ & 0.76 & 2.27 & 1.61 to 3.19 & $<0.001$ \\
\hline Never $(n=67)$ & $98 / 41$ & 0.34 & & & \\
\hline \multicolumn{6}{|l|}{ Maternal smoking } \\
\hline Yes $(n=41)$ & $124 / 36$ & 0.71 & 1.31 & 0.97 to 1.77 & 0.075 \\
\hline No $(n=127)$ & 289/97 & 0.54 & & & \\
\hline \multicolumn{6}{|c|}{ Highest parental education level for both parents } \\
\hline Completed year $10(n=24)$ & $82 / 18$ & 0.83 & 1.00 & & 0.385 \\
\hline Completed secondary education $(n=39)$ & $82 / 29$ & 0.51 & 0.62 & 0.34 to 1.14 & \\
\hline Trade $(n=76)$ & $180 / 62$ & 0.56 & 0.68 & 0.38 to 1.21 & \\
\hline Completed tertiary education $(n=17)$ & $34 / 13$ & 0.46 & 0.55 & 0.27 to 1.14 & \\
\hline \multicolumn{6}{|l|}{ Age } \\
\hline $0-1$ year $(n=168)$ & $64 / 46$ & 0.58 & 1.00 & & 0.778 \\
\hline$>1-2$ years $(n=165)$ & $88 / 69$ & 0.59 & 1.01 & 0.73 to 1.40 & \\
\hline$>2-3$ years $(n=161)$ & $95 / 80$ & 0.66 & 1.13 & 0.79 to 1.62 & \\
\hline$>3-4$ years $(n=159)$ & $80 / 68$ & 0.55 & 0.96 & 0.66 to 1.38 & \\
\hline$>4-5+$ years $(n=158)$ & $86 / 72$ & 0.55 & 0.95 & 0.65 to 1.38 & \\
\hline \multicolumn{6}{|l|}{ Total exacerbations } \\
\hline QLD $(n=60)$ & $183 / 54$ & 0.71 & & & 0.021 \\
\hline VIC $(n=40)$ & $102 / 27$ & 0.60 & & & \\
\hline NSW and SA $(n=42)$ & $70 / 32$ & 0.43 & & & \\
\hline$N Z(n=26)$ & $58 / 20$ & 0.51 & & & \\
\hline \multicolumn{6}{|l|}{ Exacerbations reported by clinic doctor } \\
\hline $\mathrm{QLD}(n=60)$ & $151 / 51$ & 0.57 & & & 0.083 \\
\hline VIC $(n=40)$ & $55 / 21$ & 0.31 & & & \\
\hline NSW and SA $(n=42)$ & $66 / 31$ & 0.40 & & & \\
\hline$N Z(n=26)$ & $53 / 18$ & 0.46 & & & \\
\hline
\end{tabular}


trials, their frequency and clinical features in this age group and their relationship to long-term clinical outcomes need to be understood. As part of achieving a standardised definition of 'respiratory exacerbations' in young children it is also important to include parental observations across varying levels of disease severity. ${ }^{7}$

We therefore sought to describe the rate, clinical features and duration of respiratory exacerbations in children diagnosed with CF after newborn screening and followed until 5 years of age; to determine if any features discriminated between mild (community-managed) and more serious (hospital-admission) episodes; and to characterise associations with growth and lung structure and function at age 5 years.

\section{METHODS}

\section{Subjects and design}

This study was a secondary analysis of the Australasian CF BronchoAlveolar Lavage randomised controlled trial (RCT) involving eight CF centres (Australian Clinical Trials Registry ACTRN012605000665639; http://www.actr.org.au/), which has been described previously in detail. ${ }^{8}$ Ethics Committees from each participating centre approved the study and informed caregiver consent was given before enrolment.

Eligible infants were aged less than 6 months and diagnosed with 'classic' CF (at least two of the following: two CF mutations, sweat chloride $>60 \mathrm{mmol} /$ litre, pancreatic insufficiency or meconium ileus) subsequent to newborn screening in the Australian states of New South Wales (NSW), Queensland, South Australia (SA) and Victoria, and throughout New Zealand (NZ) between June 1999 and April 2005 inclusive.

In brief, this was a clinical trial in which infants were randomly assigned in a 1:1 ratio, stratified by site (Australian state or NZ) and gender, to receive either bronchoalveolar lavage (BAL)-directed therapy or standard management from under 6 months of age until 5 years of age. A routine clinic review was undertaken at least every 3 months. Infants recruited in two states (NSW and SA) only were prescribed antibiotic prophylaxis (flucloxicillin) during their first year of life.

Respiratory exacerbations were defined as 'any change in respiratory symptoms from baseline' to try and capture all episodes as far as possible. These were documented on a standardised questionnaire with all the parameters making up the individual episode, and reported by either family alone or family and physician at clinic visits when an oropharyngeal swab was taken. Hospital admission occurred if the oropharyngeal swab grew Pseudomonas aeruginosa, or the treating physician deemed it necessary because of illness severity, or failure to improve after 6 weeks of community treatment. Otherwise, children were managed at home (community management) where initially flucloxicillin was increased (prophylactic group) or prescribed (non-prophylactic group) and/or a second oral (non-anti-pseudomonal) antibiotic was added or substituted depending on the culture results and individual tolerance. All children were treated identically to this point. However, if hospital admission ensued, the BAL group underwent bronchoscopy and received intravenous antibiotics if the BAL culture was positive for $P$ aeruginosa or if deemed necessary clinically, while those in the standard group received intravenous antibiotics regardless. ${ }^{8}$

$P$ aeruginosa in the oropharyngeal sample (standard group) or at $\geq 10^{3}$ colony forming units $\mathrm{CFU} / \mathrm{ml}$ in BAL fluid (BAL group) resulted in 2 weeks of intravenous ticarcillin clavulanate or ceftazidime and tobramycin, followed by 2 months of inhaled tobramycin (TOBI $300 \mathrm{mg} / 5 \mathrm{ml}$ ) with 1 month of oral ciprofloxacin.
At treatment end children either underwent a further BAL (BAL group) or had oropharyngeal swabs taken (standard group). If $P$ aeruginosa persisted the eradication course was repeated and if follow-up cultures were still positive the child was deemed 'chronically infected'.

\section{Procedures}

BAL under general anaesthesia, and BAL and oropharyngeal cultures were performed as described previously. ${ }^{8}$ All children underwent additional assessments at age 5 years, including physical examination, anthropometric evaluation, oropharyngeal and BAL cultures, chest CT scans and spirometry. ${ }^{8}$ Lung function was measured post bronchodilatation using American Thoracic Society criteria. 9

\section{Analysis}

Standardised questionnaires were completed for visits at 'randomisation', for 'routine reviews', 'exacerbations' and 'exacerbation reviews'. Exacerbation duration was estimated from the dates recorded on the 'exacerbation' and 'exacerbation review' forms and when necessary the hospital discharge or end of study date.

Bronchiectasis and air trapping on chest CT scans, interpreted blinded to clinical data, were dichotomised into either being present or absent. $\mathrm{Z}$ scores were calculated for weight using the 2000 CDC Growth Reference Charts (http://www.cdc.gov/ growthcharts); forced expiratory volume in $1 \mathrm{~s}\left(\mathrm{FEV}_{1}\right)$ using British reference values (http://www.lungfunction.org/ growinglungs); and respiratory rate counted over $1 \mathrm{~min}$ by using published age-related standards. ${ }^{10}$

Group comparisons are presented with 95\% CI and twosided $\mathrm{p}$ values with logistic regression used to estimate OR for dichotomous outcomes and $t$ tests or linear regression for mean comparisons with continuous outcomes. Skewed data underwent logarithmic transformation with medians and IQR presented. Incidence of exacerbations is summarised as a rate per person-years of follow-up time (stratified by age, randomised treatment group, gender, site, prophylaxis, $P$ aeruginosa infection 'ever', maternal smoking and parental education level). Incidence rate ratios were estimated using Poisson regression analysis, with allowance for over-dispersion attributable to variation between patients. For regression analyses of associations between exacerbation rates and later outcomes, incidence rates were transformed to $\log$ base 2 where exacerbation rate was the explanatory variable, while natural logs were used when exacerbation rate was the outcome variable (years 4 and 5). The former scaling meant that regression coefficients and OR represented expected change in outcome per doubling of early-life exacerbation rate, while the latter produced the standard logbased interpretation of expected change in outcome in percentage terms relative to small differences in predictor values. ${ }^{11}$ When comparisons involved repeated measures from the same patient, standard errors allowing for clustering effects were calculated using the robust 'information sandwich' method. Analysis was performed using Stata V.12.1.

\section{RESULTS}

Overall, 170 children were enrolled (86 to standard group, 84 receiving allocated intervention, and 84 to the BAL group) at a mean age of 3.6 (SD 1.6) months with 157 (77 standard group and 80 BAL group, $92 \%$ of the total) completing the study. 8

There were 2080 respiratory exacerbations in 166 children (range 0-29 per child), an incidence rate of 3.66 episodes per 
Parent Reported

$(n=2069)$

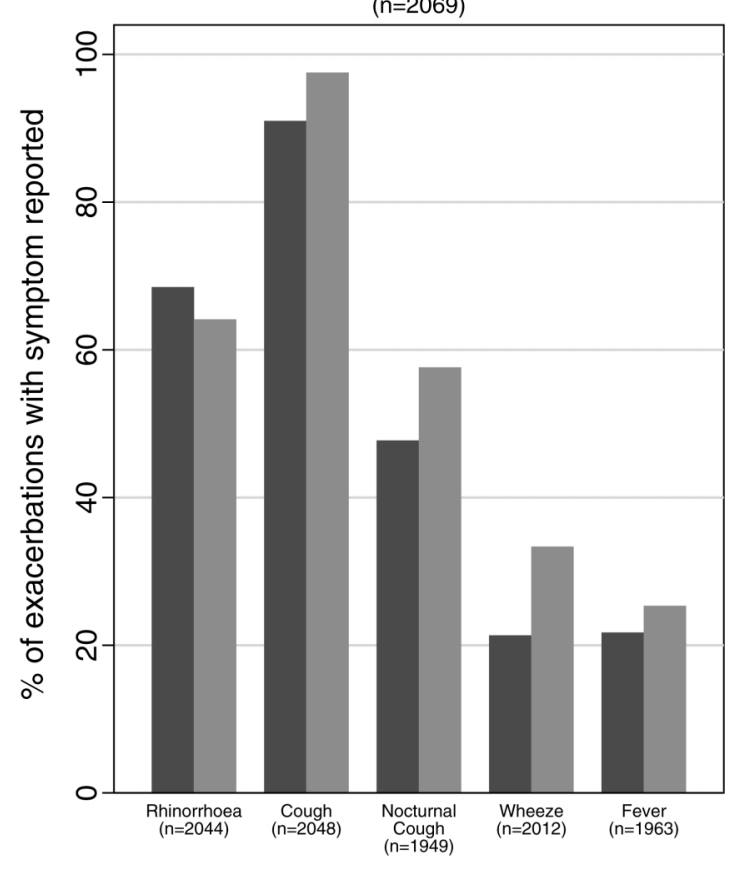

Doctor Reported

$(n=1263)$

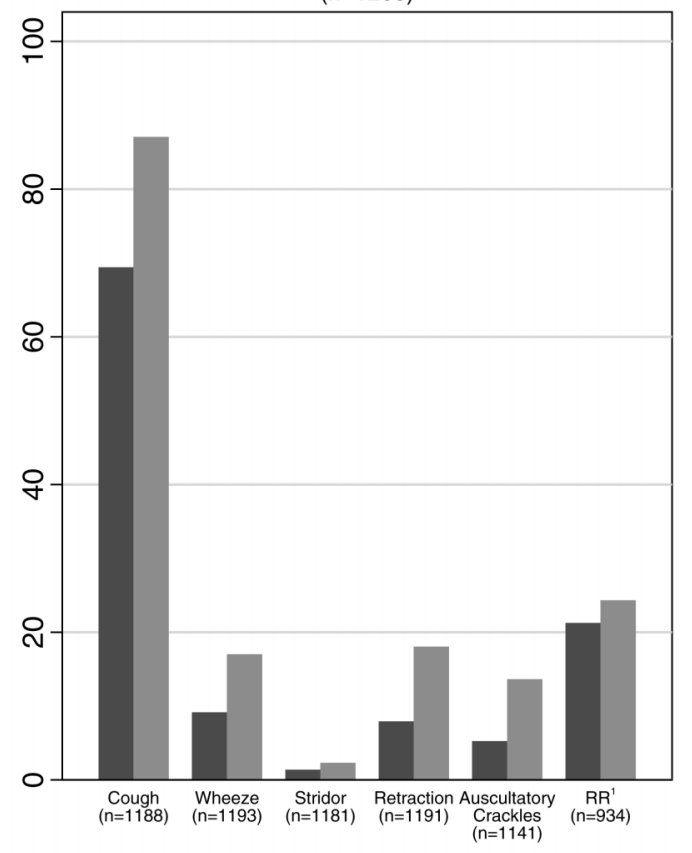

Hospital Admission

Figure 1 Features of respiratory exacerbations according to whether 'community managed' or 'hospital admission'. 'Respiratory rate $z$ score more than 2 SDs from the mean. ${ }^{10}$

person-year. Of these, 1667 (80.1\%) in 164 children were community managed (93.4\% had antibiotics) and $413(19.9 \%)$ in 133 children required hospitalisation. The median duration was 22 days (IQR 14-38) for community-managed exacerbations and 50 days (IQR 26-85) for hospital-admission episodes $(p<0.001)$. Longer duration was also seen in those with a history of $P$ aeruginosa 'ever' (median 28 days, IQR 15-50) versus those from whom it had never been isolated (median 22 days, IQR 14-42, $\mathrm{p}=0.002$ ).

On average, the exacerbation rate increased by $9 \%(95 \% \mathrm{CI}$ $4 \%$ to $14 \% ; \mathrm{p}<0.001)$ per year of age and there was an association between site and both total and 'doctor reported' exacerbations (table 1). Similarly, children who received early antibiotic prophylaxis had lower exacerbation rates over the whole study period than those without prophylaxis. This practice was determined by site, so the apparent effect of prophylaxis cannot be separated from other factors that might have differed between sites. No evidence for differences in total exacerbation rates was observed by randomised treatment group (BAL vs standard), gender or home environment (maternal smoking or parental education levels). There was a trend towards a higher rate among those ever positive for $P$ aeruginosa, and a history of a positive $P$ aeruginosa culture was the only factor clearly associated with increased risk of hospital admission for a respiratory exacerbation (table 1). The latter is not surprising as a positive culture triggered hospitalisation for eradication treatment.

Of the 2080 reported exacerbations, parents reported 2069 and a doctor review was undertaken in 1263 (61\%) of these episodes (figure 1). For parental responses, the presence of cough, nocturnal cough, and wheeze was significantly more common in children managed in hospital. For doctor-reviewed exacerbations, cough, wheeze, tracheal tug and/or chest wall recession, and auscultatory crackles were significantly more frequent in episodes requiring hospital admission. Children admitted with $P$ aeruginosa prompted by an oropharyngeal or BAL sample but no new symptoms or signs did not have an exacerbation form filled out and are not included here. There were 32 admissions for Paeruginosa treatment outside of an exacerbation in 20 children. Associations between exacerbations in the first 5 years of life and lung structure and function, and weight-for-age $\mathrm{z}$ scores at age 5 years are presented in tables 2 and 3 . Outcomes at 5 years were consistently worse in children who ever had an exacerbation requiring hospital admission. There was evidence of an increased risk of bronchiectasis on chest CT scans, slightly weakened after adjusting for $P$ aeruginosa isolation ever (which triggered admission, table 2 ). The rate of exacerbations during the first 2 years of life was associated with a lower $\mathrm{FEV}_{1}$, even after adjusting for a history of $P$ aeruginosa infection (table 2, figure 2). Table 3 shows the associations between 5 -year outcomes and reporting of specific symptoms during exacerbations ('ever' vs 'never' reported). Unsurprisingly, the chance of a symptom ever being reported during an exacerbation increased with the number of exacerbations experienced. Worse outcomes were generally seen with higher doctor reporting of symptoms on exacerbations. This was particularly striking for $\mathrm{FEV}_{1} \mathrm{z}$-score values and doctor recorded chest wall retractions and/or tracheal tug, but also significant for high-resolution CT scan bronchiectasis and wheeze, and weight z score with retractions and wheeze. The only statistically strong association with parent reporting of symptoms was with air trapping and parent-reported wheeze. Finally, exacerbation rates during years 4 and 5 increased by $12 \%$ for each doubling of the exacerbation rate in the first 2 years of life (figure 3 ). 


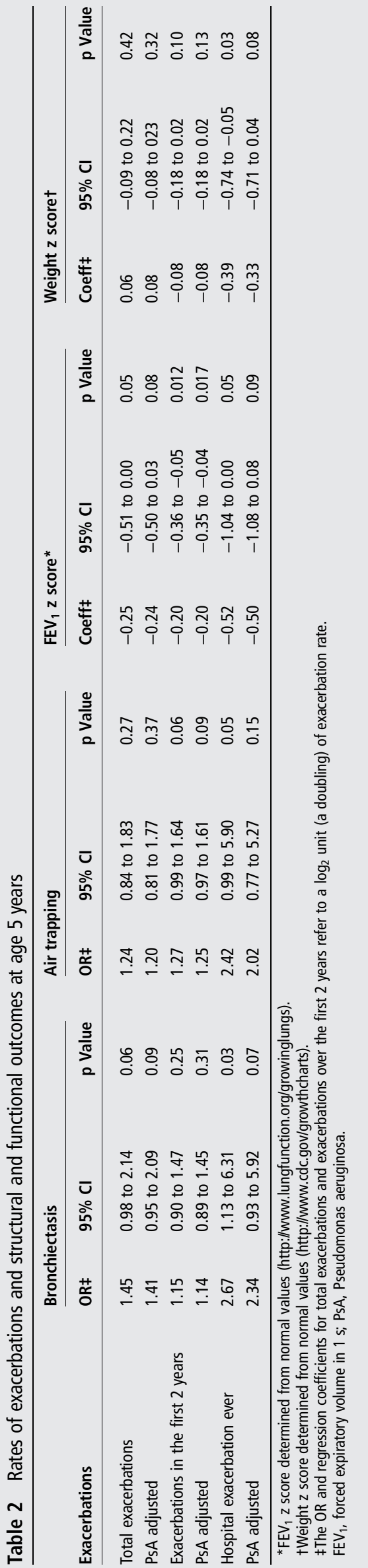

\section{DISCUSSION}

This is the first prospective study to record community and hospital managed respiratory exacerbations and their association with chest CT scan and lung function outcomes in children with CF diagnosed through newborn screening and followed to age 5 years. The children were participants in a RCT comparing BAL-directed versus standard therapy in which no differences between treatment groups were observed for the primary outcomes at 5 years of age for $P$ aeruginosa infection and structural lung injury on CT scans. ${ }^{8}$ Children had on average three to four exacerbations per year, with episodes increasing with each year of life. At 5 years the overall exacerbation rate in the first 2 years of life was associated with lower $\mathrm{FEV}_{1}$ values, while hospital-admission exacerbations were associated with increased risk of bronchiectasis and lower weight-for-age z scores.

Despite lacking a validated definition, ${ }^{12}$ exacerbations are being used widely as trial outcome measures, variably recorded as exacerbation rate, ${ }^{13}{ }^{14}$ time to exacerbation, ${ }^{14}{ }^{15}$ or time to resolution. ${ }^{16}$ 'Exacerbations' avoid the disadvantages seen with other single outcome measures, such as spirometry or CT scans in this young age group, and can be documented in community and clinic settings.

Overall, we recorded 3.66 exacerbations per child-year throughout the first 5 years of life with no differences between treatment groups or gender, but with a significant increase in exacerbation rates with age. Differences were reported between study sites, and a significant reduction was seen in children receiving anti-staphylococcal antibiotic prophylaxis up to at least 12 months of age. In contrast, prospective birth cohort studies of healthy Australian children report 4.1-6.2 acute respiratory infections per child in the first $1-2$ years of life, ${ }^{17} 18$ with rates falling to two per year by age 5 years, and an overall rate during this period of 3.4 respiratory illnesses per child-year, which is similar to our CF cohort. ${ }^{19}$

Despite using a broad definition, the reported exacerbation rate was lower than expected in these infants with CF, and we have considered possible explanations. First, we could have missed events before enrolment and throughout the study. However, the first respiratory illness in the birth cohort studies was reported between 4.2 and 6 months, and our mean enrolment age was 3.6 months. Additionally, we reviewed children with CF at least 3 monthly and more frequently when families required greater support, as during infancy or when determining exacerbation resolution. Consequently, events missed were likely to be mild as these caregivers were well educated at recognising and acting upon new respiratory symptoms. Second, while exacerbations were less frequent, their duration of 22 (community-managed) and 50 (hospital-managed) days was greater than the 4-14 days reported in healthy children. ${ }^{18} 20$ Comparisons of $\mathrm{CF}$ and non-CF siblings have also found that although their respiratory infection rates were similar, CF siblings had longer symptom duration and greater lower respiratory tract involvement. ${ }^{21}$ Third, higher infection rates in early childhood are associated with household crowding, formula feeding, low immunisation rates, passive smoking and poor nutrition, with the greatest number of respiratory infections (up to nine per year) reported in studies of healthy children attending daycare. ${ }^{17} 22$ Having received a life-limiting diagnosis for their child, some of these factors could be improved or eliminated by a motivated family. Interestingly, a recent study examining the effects of inhaled hypertonic saline on respiratory exacerbation rates in young children with CF (ISIS) reported even lower rates (2.3 events/year), although based on a more stringent definition 
Table 3 Associations between 5-year outcomes and reporting of specific symptoms/signs during exacerbations

\begin{tabular}{|c|c|c|c|c|c|c|c|c|c|c|}
\hline Outcome & Symptom & \multicolumn{3}{|c|}{$\begin{array}{l}\text { Symptom ever } \\
\text { reported }\end{array}$} & \multicolumn{3}{|c|}{$\begin{array}{l}\text { Symptom never } \\
\text { reported }\end{array}$} & OR & $95 \% \mathrm{Cl}$ & p Value \\
\hline \multicolumn{11}{|l|}{ Parent-reported symptoms } \\
\hline Bronchiectasis on CT scan ( $n=153$ ) & $\begin{array}{l}\text { Wheeze } \\
\text { Fever }\end{array}$ & \multicolumn{3}{|c|}{$\begin{array}{l}57 \%(62 / 108) \\
56 \%(75 / 133)\end{array}$} & \multicolumn{3}{|c|}{$\begin{array}{l}56 \%(25 / 45) \\
60 \%(12 / 20)\end{array}$} & $\begin{array}{l}1.08 \\
0.86\end{array}$ & $\begin{array}{l}0.53 \text { to } 2.17 \\
0.33 \text { to } 2.25\end{array}$ & $\begin{array}{l}0.83 \\
0.76\end{array}$ \\
\hline Air trapping on CT scan ( $n=154)$ & $\begin{array}{l}\text { Wheeze } \\
\text { Fever }\end{array}$ & \multicolumn{3}{|c|}{$\begin{array}{l}54 \%(59 / 110) \\
43 \%(58 / 134)\end{array}$} & \multicolumn{3}{|c|}{$\begin{array}{l}25 \%(11 / 44) \\
60 \%(12 / 20)\end{array}$} & $\begin{array}{l}3.47 \\
0.51\end{array}$ & $\begin{array}{l}1.59 \text { to } 7.56 \\
0.20 \text { to } 1.33\end{array}$ & $\begin{array}{l}0.002 \\
0.17\end{array}$ \\
\hline FEV $_{1}$ z score* $(n=128)$ & $\begin{array}{l}\text { Wheeze } \\
\text { Fever }\end{array}$ & $\begin{array}{l}\mathbf{n} \\
98 \\
112\end{array}$ & $\begin{array}{l}\text { Mean } \\
-0.55 \\
-0.48\end{array}$ & $\begin{array}{l}\text { SD } \\
1.19 \\
1.18\end{array}$ & $\begin{array}{l}\mathbf{n} \\
30 \\
16\end{array}$ & $\begin{array}{c}\text { Mean } \\
-0.13 \\
-0.26\end{array}$ & $\begin{array}{l}\text { SD } \\
1.08 \\
1.19\end{array}$ & $\begin{array}{l}\text { Diff in means } \\
-0.43 \\
-0.22\end{array}$ & $\begin{array}{l}95 \% \mathrm{Cl} \\
-0.91 \text { to } 0.06 \\
-0.84 \text { to } 0.41\end{array}$ & $\begin{array}{l}\text { p Value } \\
0.08 \\
0.49\end{array}$ \\
\hline \multicolumn{11}{|l|}{ Weight z scoret ( $n=157$ ) } \\
\hline & $\begin{array}{l}\text { Wheeze } \\
\text { Fever }\end{array}$ & $\begin{array}{l}111 \\
135\end{array}$ & $\begin{array}{l}-0.24 \\
-0.14\end{array}$ & $\begin{array}{l}0.85 \\
0.85\end{array}$ & $\begin{array}{l}46 \\
22\end{array}$ & $\begin{array}{l}-0.03 \\
-0.45\end{array}$ & $\begin{array}{l}0.84 \\
0.80\end{array}$ & $\begin{array}{l}-0.21 \\
0.31\end{array}$ & $\begin{array}{l}-0.50 \text { to } 0.09 \\
-0.07 \text { to } 0.70\end{array}$ & $\begin{array}{l}0.16 \\
0.11\end{array}$ \\
\hline \multicolumn{11}{|l|}{ Doctor-reported symptoms } \\
\hline \multirow[t]{2}{*}{ Bronchiectasis on CT scan ( $n=153$ ) } & $\begin{array}{l}\text { Wheeze } \\
\text { Crackles }\end{array}$ & \multicolumn{3}{|c|}{$\begin{array}{l}67 \%(43 / 64) \\
62 \%(34 / 55)\end{array}$} & \multicolumn{3}{|c|}{$\begin{array}{l}49 \%(44 / 89) \\
54 \%(53 / 98)\end{array}$} & $\begin{array}{l}2.09 \\
1.37\end{array}$ & $\begin{array}{l}1.07 \text { to } 4.08 \\
0.70 \text { to } 2.70\end{array}$ & $\begin{array}{l}0.03 \\
0.36\end{array}$ \\
\hline & Chest retractions & \multicolumn{3}{|c|}{$59 \%(36 / 61)$} & \multicolumn{3}{|c|}{$55 \%(51 / 92)$} & 1.16 & 0.60 to 2.23 & 0.66 \\
\hline Air trapping on CT scan $(n=154)$ & $\begin{array}{l}\text { Wheeze } \\
\text { Crackles } \\
\text { Chest retractions }\end{array}$ & \multicolumn{3}{|c|}{$\begin{array}{l}51 \%(33 / 65) \\
55 \%(30 / 55) \\
53 \%(32 / 60)\end{array}$} & \multicolumn{3}{|c|}{$\begin{array}{l}42 \%(37 / 89) \\
40 \%(40 / 99) \\
40 \%(38 / 94)\end{array}$} & $\begin{array}{l}1.45 \\
1.77 \\
1.68\end{array}$ & $\begin{array}{l}0.76 \text { to } 2.76 \\
0.91 \text { to } 3.44 \\
0.88 \text { to } 3.24\end{array}$ & $\begin{array}{l}0.26 \\
0.09 \\
0.12\end{array}$ \\
\hline FEV $_{1}$ z score ${ }^{*}(n=128)$ & $\begin{array}{l}\text { Wheeze } \\
\text { Crackles } \\
\text { Chest retractions }\end{array}$ & $\begin{array}{l}n \\
54 \\
44 \\
51\end{array}$ & $\begin{array}{l}\text { Mean } \\
-0.60 \\
-0.68 \\
-0.80\end{array}$ & $\begin{array}{l}\text { SD } \\
1.26 \\
1.32 \\
1.30\end{array}$ & $\begin{array}{l}\mathbf{n} \\
74 \\
84 \\
77\end{array}$ & $\begin{array}{l}\text { Mean } \\
-0.34 \\
-0.33 \\
-0.22\end{array}$ & $\begin{array}{l}\text { SD } \\
1.11 \\
1.09 \\
1.03\end{array}$ & $\begin{array}{l}\text { Diff in means } \\
-0.25 \\
-0.34 \\
-0.59\end{array}$ & $\begin{array}{l}95 \% \mathrm{Cl} \\
-0.67 \text { to } 0.16 \\
-0.77 \text { to } 0.09 \\
-1.00 \text { to }-0.18\end{array}$ & $\begin{array}{l}p \text { Value } \\
0.23 \\
0.12 \\
0.005\end{array}$ \\
\hline \multicolumn{11}{|l|}{ Weight $z$ scoret $(n=157$ ) } \\
\hline & $\begin{array}{l}\text { Wheeze } \\
\text { Crackles } \\
\text { Chest retractions }\end{array}$ & $\begin{array}{l}66 \\
55 \\
62\end{array}$ & $\begin{array}{l}-0.34 \\
-0.20 \\
-0.37\end{array}$ & $\begin{array}{l}0.86 \\
0.80 \\
0.88\end{array}$ & $\begin{array}{l}91 \\
102 \\
95\end{array}$ & $\begin{array}{l}-0.07 \\
-0.17 \\
-0.06\end{array}$ & $\begin{array}{l}0.82 \\
0.88 \\
0.81\end{array}$ & $\begin{array}{l}-0.27 \\
-0.03 \\
-0.31\end{array}$ & $\begin{array}{l}-0.54 \text { to } 0.00 \\
-0.31 \text { to } 0.25 \\
-0.58 \text { to }-0.04\end{array}$ & $\begin{array}{l}0.05 \\
0.85 \\
0.02\end{array}$ \\
\hline
\end{tabular}

${ }^{*} \mathrm{FEV}_{1} \mathrm{z}$ score determined from normal values (http://www.lungfunction.org/growinglungs).

tWeight z-score determined from normal values (http://www.cdc.gov/growthcharts).

Diff in means, difference in means; $\mathrm{FEV}_{1}$, forced expiratory volume in $1 \mathrm{~s}$; $\mathrm{SD}$, standard deviation.

including the need for antibiotic treatment. We have re-examined the total exacerbations reported in our study and determined that $90.4 \%$ would have also met the ISIS study criteria. ${ }^{23}$

A lower exacerbation rate with anti-staphylococcal antibiotic prophylaxis was an interesting finding. A Cochrane review found that this approach reduced Staphylococcus aureus culture rates, but importantly not hospitalisation or antibiotic use. $^{24}$ Our study was not designed to address this issue and prophylaxis was determined by research sites where

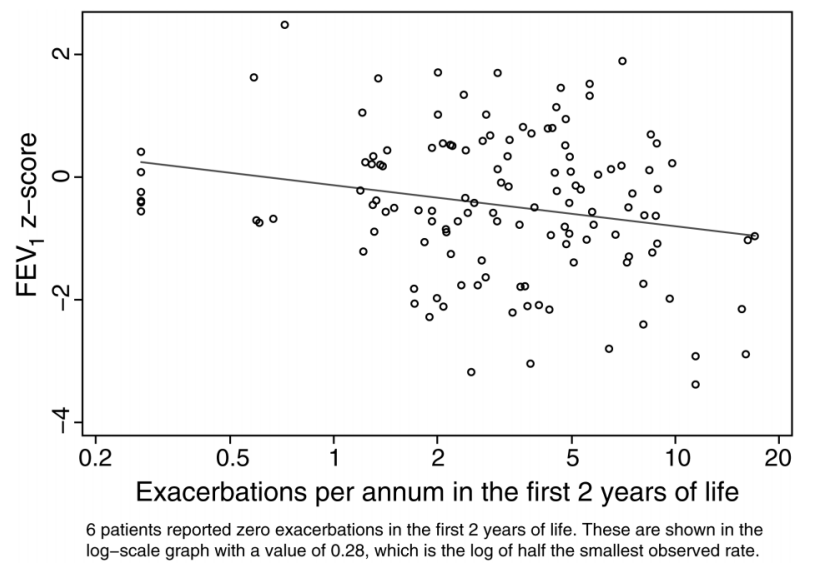

Figure 2 Forced expiratory volume in $1 \mathrm{~s}$ (FEV1) z score versus respiratory exacerbation rate during the first 2 years of life. Six patients reported 0 exacerbations in the first 2 years of life. These are shown in the log-scale graph with a value of 0.28 , which is the log of half the smallest observed rate. significantly lower exacerbation rates were recorded. Knowing children were already taking antibiotics may have resulted in a higher threshold for reporting symptoms or caregivers simply

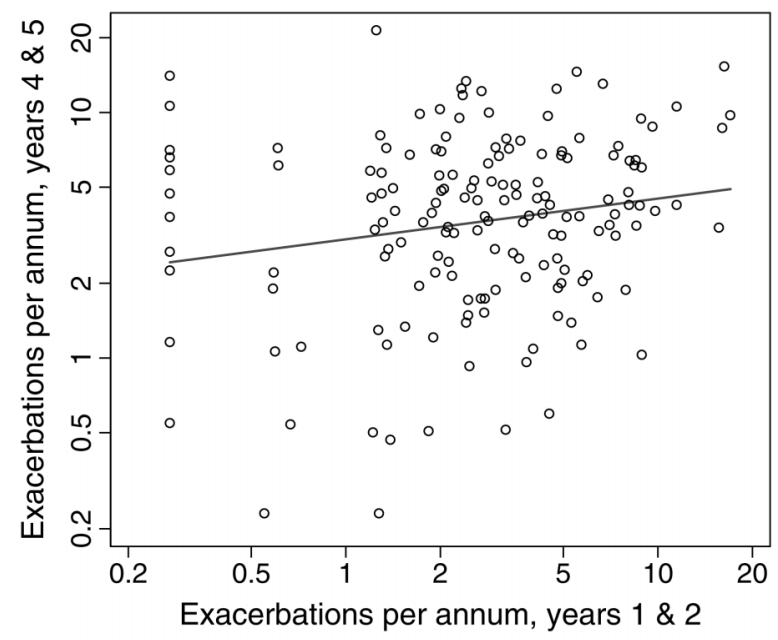

11 and 2 patients reported zero exacerbations in years $1 \& 2$, and $4 \& 5$, respectively. These are shown in the log-scale graph with a value of 0.28 or 0.23 , which is the log of half the smallest observed rate in each pair of years.

Figure 3 Rate of respiratory exacerbations in years 4 and 5 versus years 1 and 2 of life. Eleven and two patients reported 0 exacerbations in years 1 and 2, and 4 and 5, respectively. These are shown in the log-scale graph with a value of 0.28 or 0.23 , which is the log of half the smallest observed rate in each pair of years. 
increasing the dose without reporting this at subsequent reviews.

Our study definition of 'exacerbation' avoided the need for either antibiotic treatment or medical review, thereby attempting to capture as many episodes as possible. The presence of cough, wheeze, chest wall recession and auscultatory crackles was significantly more common in exacerbations requiring hospital admission but no single feature was able to reliably predict this course. Although several scoring systems have been developed, these have been mainly for older children and adults, ${ }^{12} 25-27$ those chronically infected with $P$ aeruginosa,${ }^{12}$ requiring hospital treatment ${ }^{26}$ or included spirometery. ${ }^{26}$ The 'Acute Respiratory Illness Checklist' was developed to evaluate a candidate respiratory syncytial virus vaccine in 34 children with $\mathrm{CF}$ aged 1.6-7.9 years. ${ }^{28}$ This required at least three parameters for upper and five parameters for lower respiratory infections. The need for a standardised definition of a respiratory exacerbation was first recommended in 1994, and now another is required specifically for infancy and early childhood. ${ }^{29}$

We found a statistically significant association between exacerbations requiring hospitalisation and bronchiectasis in the 5 years of age high-resolution CT scan. Exacerbations are associated with disease progression in older age groups with $\mathrm{CF}^{2}{ }^{4}$ Of interest, in 61 children aged 6-10 years, CT scans performed at baseline prior to a rhDNAse trial showed that 'total', 'bronchiectasis' and 'mucous plugging' scores correlated significantly with respiratory exacerbation rate. The change in scores with chest CT scans 2 years later also correlated with respiratory exacerbations, most strongly with bronchiectasis. ${ }^{30}$ The AREST CF group also reported the presence and extent of bronchiectasis increased from $8.5 \%$ in the first year to $36 \%$ by age 4 years in 96 children with CF and was associated with $P$ aeruginosa infection, but not hospitalised days for respiratory illness. ${ }^{31}$

The exacerbation rate in the first 2 years of life was associated with reduced $\mathrm{FEV}_{1}$ at age 5 years, which remained when adjusting for $P$ aeruginosa infection. In contrast, in the rhDNAse study lung function parameters did not correlate with the number of respiratory infections at baseline or over the 2-year study period. ${ }^{30}$ However, two further studies reported an association between respiratory symptoms and lower lung function in young children with CF during stable health. ${ }^{32}{ }^{33}$ Moreover, in 37 infants, a greater decline was reported in forced vital capacity and $\mathrm{FEV}_{0.5}$ across a 1-year or 2-year period when neutrophil elastase, $S$ aureus or $P$ aeruginosa were present in contemporaneous BAL cultures. ${ }^{34}$ As new $P$ aeruginosa infection triggered hospitalisation, we cannot comment on this effect in our study.

Exacerbations requiring hospital admission resulted in lower weight-for-age $\mathrm{z}$ scores at age 5 years, while parent-reported wheeze predicted air trapping on CT scans and doctor-reported chest wall retractions predicted a lower $\mathrm{FEV}_{1}$ score. Finally, the data suggested that children with higher rates of respiratory exacerbations in the first 2 years of life continued to experience higher rates in years 4 and 5 . This is consistent with prospective studies in healthy children that described tracking of highrespiratory infection rates in infancy into older age groups and this may be a marker for more severe disease progression. ${ }^{17} 20$

In conclusion, this prospective study following children diagnosed with $\mathrm{CF}$ subsequent to newborn screening to age 5 years found a respiratory exacerbation rate of 3.66 episodes per childyears. On average the exacerbation rate increased by $9 \%$ per year of age. While certain clinical features were seen more often in severe exacerbations, no single parameter reported by either parents or doctors predicted the need for hospital admission. Higher exacerbation rates in the first 2 years of life resulted in a lower $\mathrm{FEV}_{1}$ and higher exacerbations rates in later years, and exacerbations requiring hospital admission were associated with bronchiectasis and lower weight-for-age $\mathrm{z}$ scores at 5 years. These findings emphasise the importance of pulmonary exacerbations in the first years of life. They also raise the possibility of different disease mechanisms operating. Repeated mild-to-moderate exacerbations managed in the community may result in airway remodelling, while more severe hospitalised episodes could increase structural airway injury risk. Further studies are required to identify whether such differences exist and whether these should be considered when introducing novel treatments to reduce early CF lung injury.

\section{Author affiliations}

${ }^{1}$ Department of Paediatrics, University of Auckland, Auckland, New Zealand ${ }^{2}$ Department of Paediatric Respiratory Medicine, Starship Children's Health, Auckland, New Zealand

${ }^{3}$ Clinical Epidemiology and Biostatistics Unit, Murdoch Children's Research Institute, Melbourne, Australia

${ }^{4}$ Department of Paediatrics, University of Melbourne, Melbourne, Australia ${ }^{5}$ Queensland Children's Medical Research Institute, Royal Children's Hospital, University of Queensland, Brisbane, Australia

${ }^{6}$ Queensland Children's Respiratory Centre, Royal Children's Hospital, Brisbane, Australia

${ }^{7}$ Department of Paediatrics, Monash Medical Centre, Melbourne, Australia

${ }^{8}$ Department of Respiratory Medicine, The Children's Hospital at Westmead, Sydney, Australia

${ }^{9}$ Department of Infectious Disease, Royal Children's Hospital, Brisbane, Australia

${ }^{10}$ Deakin Health Economics, Population Health Strategic Research Centre, Deakin University, Melbourne, Australia

${ }^{11}$ Department of Respiratory Medicine, Royal Children's Hospital, Melbourne, Australia

${ }^{12}$ Center for Clinical and Translational Research, Seattle Children's Hospital, Seattle, Washington, USA

${ }^{13}$ Department of Pediatrics, University of Washington, Seattle, Washington, USA

${ }^{14}$ Department of Pediatric Pulmonology, Erasmus Medical Centre, Sophia Children's Hospital, Rotterdam, The Netherlands

Collaborators The following investigators constitute the ACFBAL Study Investigators Group: Brisbane, Australia: Claire E Wainwright, ${ }^{*}$ Keith Grimwood, ${ }^{*}$ Joyce Cheney† (Queensland Children's Medical Research Institute, University of Queensland), Paul W Francis* (Royal Children's Hospital), Carolyn Dakin* (Mater Children's Hospital), Narelle George (Pathology Queensland); Melbourne, Australia: John B Carlin, ${ }^{*}$ Suzanna Vidmart (Murdoch Children's Research Institute), Colin F Robertson, ${ }^{*}$ Rosemary Carzino† (Royal Children's Hospital), Marj Moodie, $†$ Robert Carter, ${ }^{*} \dagger$ Anita Lal (Deakin University), David S Armstrong ${ }^{*}$ (Monash Medical Centre); Sydney, Australia: Peter J Cooper, ${ }^{*}$ Karen McKay (The Children's Hospital at Westmead); Adelaide, Australia: A (James) Martin* (Womens \& Children's Hospital); Newcastle, Australia: Bruce Whitehead* (John Hunter Children's Hospital); Auckland, New Zealand: Catherine A Byrnes*, Merrin Harger, Jan Tate (University of Auckland and Starship Children's Health); Rotterdam, The Netherlands: Harm A Tiddens, ${ }^{*}$ Karla Graniel, Krista Gerbrands, Lauren Mott (Erasmus Medical Centre). *Indicates principal investigator or director. †Received part or full salary from National Health Medical Research Council or Children's Health Foundation Queensland grant funding.

Contributors $C A B$ helped design the study, was the principal investigator in New Zealand, supervised the research conduct including ethics and grant for the NZ site, led data collection in NZ, participated in analysis, led drafting of this manuscript and submitted the final manuscript approved by all authors. SV advised on data collection, led data processing and statistical advice, undertook data collection checks and data cleaning, conducted the statistical analysis, contributed to writing the manuscript, and helped develop the tables and the figures for the manuscript. JLC was the primary coordinator for the study, for all study sites, assisting with ethics and grant applications, for the data collection and data checking, communication, participated in analysis, drafting and submission of the manuscript. $\mathrm{JBC}$ led the statistical analysis, was involved in designing the study, statistical analysis and data interpretation, drafting the manuscript and approved final version. DSA was involved in designing the study, led coordination and data collection at one of the sites, data interpretation, drafting the manuscript and approved the final version. PJC was involved in designing the study, led coordination and data collection at one of the sites, data interpretation, drafting the manuscript and approved the final version. KG was involved in designing the study, led investigation and interpretation of the microbiological data, was involved in overall data interpretation, drafting and revising the manuscript and approved the final version. 
MM was involved in designing the study, assisted with costing and economics of the study, data interpretation, drafting the manuscript and approved the final version. CFR was involved in conceptualising and designing the study, led coordination and data collection at one of the sites, data interpretation, drafting the manuscript and approved the final version. MR assisted with the original concept of the study, was involved in data interpretation of exacerbations, drafting the manuscript and approved the final version. HAT was involved in designing the study, led the interpretation of the radiology data from all sites, was involved in overall data interpretation, drafting the manuscript and approved the final version. CEW was the principal investigator for the study, was involved in conceptualising and designing the study, coordinated the study over all study sites and investigation sites, led the original ethics applications and grant applications, led coordination and data collection at one of the sites, overall data interpretation, drafting the manuscript and approved the final version.

Funding The study was supported by grants from the National Health and Medical Research Council, Australia (ID No. 9937868 and 351541); the Children's Health Foundation Queensland, Australia; Faculty Research Development Fund, Faculty of Medical and Health Sciences, The University of Auckland, New Zealand (No. 3609468/9304). In addition, the Pathogenesis Corporation, Chiron Corporation and Novartis Pharmaceuticals supplied TOBI throughout the study. The funding bodies and Pathogenesis Corporation, Chiron Corporation and Novartis Pharmaceuticals did not play any role in the design and conduct of the study; collection, management, analysis, and interpretation of the data; or preparation, review or approval of the manuscript.

\section{Competing interests None.}

Patient consent Obtained.

Ethics approval Queensland Children's Health Services (RCH) Human Research Ethics Committee (HREC) and Northern Y Ethics Committee, New Zealand.

Provenance and peer review Not commissioned; internally peer reviewed.

Data sharing statement The Australiasian Cystic Fibrosis BronchoAlveolar Lavage research group-listed in the authorship - potentially have access to the ACFBAL data. Any decisions regards use of the data or publications within the group and/or access to the data from outside the group must be discussed and agreed by a core panel designated by the ACFBAL researchers.

Open Access This is an Open Access article distributed in accordance with the Creative Commons Attribution Non Commercial (CC BY-NC 3.0) license, which permits others to distribute, remix, adapt, build upon this work non-commercially, and license their derivative works on different terms, provided the original work is properly cited and the use is non-commercial. See: http://creativecommons.org/ licenses/by-nc/3.0/

\section{REFERENCES}

1 VanDevanter DR, Yegin A, Morgan WJ, et al. Design and powering of cystic fibrosis clinical trials using pulmonary exacerbation as an efficacy endpoint. J Cystic Fibros 2011;10:453-9.

2 Sanders DB, Bittner RCL, Rosenfeld $M$, et al. Pulmonary exacerbations are associated with subsequent $\mathrm{FEV}_{1}$ decline in both adults and children with cystic fibrosis. Pediatr Pulmonol 2011;46:393-400.

3 Britto $M$, Kotagal $U$, Hornung $R$, et al. Impact of recent pulmonary exacerbations on quality of life in patients with cystic fibrosis. Chest 2002;121:64-72.

4 de Boer $\mathrm{K}$, Vandemheen $\mathrm{KL}$, Tullis $\mathrm{E}$, et al. Exacerbation frequency and clinical outcomes in adult patients with cystic fibrosis. Thorax 2011:66:680-5.

5 Cystic Fibrosis Foundation. Clinical Practice Guidelines for Cystic Fibrosis. Bethesda, MD: Cystic Fibrosis Foundation, 1997

6 Rabin HR, Butler SM, Wohl ME, et al. Pulmonary exacerbations in cystic fibrosis. Pediatr Pulmonol 2004;37:400-6.

7 Abbott J, Holt A, Morton AM, et al. Patient indicators of a pulmonary exacerbation: preliminary reports from school aged children map onto those of adults. J Cyst Fibros 2012;11:180-6.

8 Wainwright CE, Vidmar S, Armstrong DS, et al. Effect of bronchoalveolar lavage-directed therapy on Pseudomonas aeruginosa infection and structural lung injury in children with cystic fibrosis. JAMA 2011;306:163-71.
9 American Thoracic Society. Standardization of spirometery, 1994 update. Am J Respir Crit Care Med 1995;152:1107-36.

10 Fleming $\mathrm{S}$, Thompson $\mathrm{M}$, Stevens $\mathrm{R}$, et al. Normal ranges of heart rate and respiratory rate in children from birth to 18 years of age: a systematic review of observational studies. Lancet 2011;377:1011-18.

11 Cole TJ. Sympercents: symmetric percentage differences on the 100 loge scale simplify the presentation of log transformed data. Stat Med 2000;19:3109-25.

12 Rosenfeld M, Emerson J, Williams-Warren J, et al. Defining a pulmonary exacerbation in cystic fibrosis. J Pediatrics 2001;139:359-65.

13 Elkins MR, Robinson M, Rose BR, et al. A controlled trial of long-term inhaled hypertonic saline in patients with cystic fibrosis. N Engl J Med 2006;354:229-40.

14 Saiman L, Marshall BC, Mayer-Hamblett N, et al. Azithromycin in patients with cystic fibrosis chronically infected with Pseudomonas aeruginosa. JAMA 2003:290:1749-56.

15 Balfour-Lynn IM, Lees B, Hall P, et al. Multicenter randomized controlled trial of withdrawal of inhaled corticosteroid in cystic fibrosis. Am J Respir Crit Care Med 2006;173:1356-62.

16 Vic $P$, Atego $S$, Turck D, et al. Efficacy, tolerance, and pharmacokinetics of once daily tobramycin for pseudomonas exacerbation in cystic fibrosis. Arch Dis Child 1998:78:536-9.

17 Douglas RM, Woodward A, Miles $\mathrm{H}$, et al. A prospective study of proneness to acute respiratory illness in the first two years of life. Int J Epidemiol 1994;23:818-26.

18 Kusel MMH, de Klerk NH, Holt PG, et al. Role of respiratory viruses in acute upper and lower respiratory tract illness in the first year of life. Pediatr Infect Dis $J$ 2006:25:680-6.

19 Kusel MMH, de Klerk NH, Holt PG, et al. Occurrence and management of acute respiratory illnesses in early childhood. I Paediatr Child Health 2007:43:139-46.

20 Gruber C, Keil T, Kulig M, et al. History of respiratory infections in the first 12 yr among children from a birth cohort. Pediatr Allergy Immunol 2008;19:505-12

21 Ramsey BW, Gore EJ, Smith AL, et al. The effect of respiratory viral infections on patients with cystic fibrosis. Am J Dis Child 1989;143:662-8.

22 Schwartz B, Giebink GS, Henderson FW, et al. Respiratory infections in day care. Pediatrics 1994;94:1018-20

23 Rosenfeld M, Ratjen F, Brumback L, et al. Inhaled hypertonic saline in infants and children younger than 6 years with cystic fibrosis. The ISIS randomized controlled trial. JAMA 2012:307:2269-77.

24 Smyth AR, Walters S. Prophylactic anti-staphylococcal antibiotics for cystic fibrosis. Cochrane Database Syst Rev 2003;(3):CD001912.

25 Jarad NA, Sequeiros IM. A novel respiratory system scoring system for CF pulmonary exacerbations. QJM 2012;105:137-43.

26 Kanga J, Kuhn R, Craigmyle L, et al. Cystic fibrosis clinical score: a new scoring system to evaluate acute pulmonary exacerbation. Clin Therapeutics 1999:21:1343-56.

27 Goss $\mathrm{CH}$, Burns JL. Exacerbations in cystic fibrosis 1: Epidemiology and pathogenesis. Thorax 2007;62:360-7.

28 Piedra PA, Grace $S$, Jewell $A$, et al. Purified fusion protein vaccine protects against lower respiratory tract illness during respiratory syncytial virus season in children with cystic fibrosis. Pediatr Infect Dis J 1996;15:23-31.

29 Ramsey BW, Boat TF. Outcome measures for clinical trials in cystic fibrosis. Summary of a Cystic Fibrosis Foundation consensus conference. J Pediatr 1994; 124:177-92.

30 Brody AS, Sucharew H, Campbell JD, et al. Computed tomography correlates with pulmonary exacerbations in children with cystic fibrosis. Am J Respir Crit Care Med 2005:172:1128-32.

31 Stick SM, Brennan S, Murray C, et al. Bronchiectasis in infants and preschool children diagnosed with cystic fibrosis after newborn screening. J Pediat 2009:155:623-8

32 Gangell $\mathrm{CL}$, Horak F, Patterson $\mathrm{HJ}$, et al. Respiratory impedence in children with cystic fibrosis using forced oscillations in clinic. Eur Respir J 2007:30:892-7.

33 Beydon N, Amsallem F, Bellet $\mathrm{M}$, et al. Pulmonary function test in preschool children with cystic fibrosis. Am J Respir Crit Care Med 2002;166:1099-104.

34 Pillarisetti $N$, Williamson $\mathrm{E}$, Linnane $\mathrm{B}$, et al. Infection, inflammation, and lung function decline in infants with cystic fibrosis. Am J Respir Crit Care Med 2011;184:75-81. 